\title{
ATIVIDADE PARA ENSINO DE INGLÊS PARA CRIANÇAS: NEGOCIAÇÃO DE SIGNIFICADOS NO ESPAÇO DE FORMAÇÃO \\ CONTINUADA.
}

\author{
Jozélia Jane Corrente Tanaca \\ (PPGEL/UEL) \\ Elaine Fernandes Mateus (UEL)
}

Este trabalho tem o objetivo de analisar práticas de aprendizagem expansiva (ENGESTROM, 1987) em contexto de formação continuada de professoras de Inglês para crianças. Compreendida como um processo complexo de negociação discursiva inerentemente plural, híbrida e dialógica, a aprendizagem expansiva será investigada tomando-se por referência categorias de discurso de autoridade e discurso internamente persuasivo (BAKHTIN, 2009). Discurso de autoridade possui estrutura compacta e fechada atuando na manutenção e estabilidade de significados. Discurso internamente persuasivo, ao contrário, é aberto a réplicas que absorvem e (re) significam sentidos socialmente cristalizados por práticas discursivas. Os dados decorrem de gravações transcritas de três grupos de estudos, realizados em 2013 com professoras e coordenadoras do Projeto Londrina Global, no município de Londrina-PR e coordenadora do projeto Desenvolvimento de Atividades de Ensino de Inglês para crianças (DAEIC/UEL, 2013). Resultados indicam movimento de resistência e expansão quanto ao significado de atividades de ensino. Este estudo ancora-se na perspectiva de aprendizagem sociocultural, que concebe aprendizagem e desenvolvimento como fenômenos processuais, não lineares e mediados (VYGOTSKY, 1988, 2001; JOHNSON, 2009), nos conceitos de aprendizagem expansiva (ENGESTROM, SANNINO, 2010), comunidade de prática (WENGER, 1998), e na concepção de discurso como prática social (FAIRCLOUGH, 2003; RAMALHO e RESENDE, 2008).

Palavras-chave: Negociação de significados. Inglês para crianças. Resistência. Aprendizagem expansiva. Projeto Londrina Global.

\section{INTRODUÇÃO}

Sob as lentes de teorias socioculturais de aprendizagem e formação de professores de línguas estrangeiras (MATEUS, 2005; 2006; JOHNSON, 2006; LIBERALI e MAGALHAES, 2009; EDWARDS, 2010; LIBERALI, 2013) atendemos, neste trabalho, ao desafio proposto por Johnson $(2006$, p. 236) de examinar e refletir sobre nossas práticas sociais (discursivas) e o papel de formadoras de professores, com intuito de (re) criarmos práticas que fortaleçam a aprendizagem profissional e o ensino de inglês para crianças, no complexo cenário de políticas educacionais que desconsideram esta área de atuação, como já afirmaram Santos, 2005, Tonelli e Cristóvão, 2010, Rocha, Tonelli e Silva, 2010, Tonelli e Chaguri, 2012, Gimenez, 2009, 2013, Tonelli e Gimenez, 2013, Gimenez et al, 2013, entre outros estudiosos. 


\section{SEMINÁRIO DE PESQUISA EM CIÊNCIAS HUMANAS - SEPECH \\ Humanidades, Estado e desafios didático-científicos \\ Londrina, 27 a 29 de julho de 2016}

Investigamos aprendizagens de professoras de inglês, no contexto de formação continuada, acreditando que elas reconfiguram continuamente identidades profissionais, criando possibilidade de novas ações correlacionadas à vivência de aprendizagem expansiva (ENGESTROM e SANNINO, 2010). Falamos da expansão de significados de práticas sociais que criam novas atividades, do desafio de se colocar de maneira diferente nos contextos de negociação de significados, sem saber e conhecer o diferente, de "aprender aprendendo" (JOHNSON, 2006). Nas palavras de Mateus (2014, p 337), abordamos, portanto, "aprendizagem como ocupação subjetiva de posições previamente dadas em práticas sociais, ocupação essa que se faz possível no curso da ação em práticas situadas, nas/das quais a ação discursiva é um dos elementos centrais". Em alguns aspectos, essa é uma perspectiva que se aproxima daquilo que Edwards (2010) denomina "agência relacional", cujo princípio explanatório chave é o desenvolvimento profissional situado, mediado pela criação e inovação a partir de experiências vividas e da (re) significação do trabalho coletivo.

Sob estas bases, entendemos que quanto maior o espaço para o dissenso, maior a latitude para agência, para a negociação e para a (re) significação das práticas (MATEUS, 2013). Assim, caracterizamos a negociação de significados como processo complexo, constituído de posições antagônicas, revestidas de crenças e saberes estabelecidos a partir dos lugares e papeis sociais que carregamos conosco nos momentos de interação das comunidades de prática (WENGER, 1998) que se apoiam no e pelo fazer. Estamos cientes de que o conceito de comunidade de prática é essencial para compreender o desenvolvimento de aprendizagem expansiva em contexto situado de prática. Entretanto, reconhecemos que olhar exclusivo para a "participação periférica legítima" (LAVE; WENGER, 1991) não constitui análise suficiente para compreensão da maneira como a negociação de significados ocorre neste contexto e estabelecemos conexão entre teorias de linguagem e de aprendizagem, com aparato teórico metodológico de análise do funcionamento da linguagem e desenvolvimento da aprendizagem em comunidade de prática (GEE, 2000; TUSTING, 2005; FAIRCLOUGH, 2003).

Olhamos, essencialmente, para a linguagem constituída e constitutiva de saberes e práticas socialmente cristalizadas e para os movimentos discursivos de transformação de significados destes saberes. Temos como foco analítico a maneira como vozes discursivas se alternam e interceptam na negociação de significados de atividades de ensino. Nosso objetivo é analisar práticas de aprendizagem expansiva, por meio da recorrência de discurso de autoridade e de discurso internamente persuasivo entre professoras e formadoras que (re) criam atividades de ensino de Inglês para crianças. Discurso de autoridade figura por significados fixos e imutáveis, socialmente constituídos pelo/no discurso como verdade absoluta. Discurso internamente persuasivo, ao contrário, pode ser caracterizado pela alternância de vozes e significados, com movimento de argumentação e contra argumentação pela abertura para o diálogo e diferentes maneiras de compreender e significar o objeto das situações de negociação (BAKHTIN, 2010).

O movimento de construção de significados pode ser analisado pelos estilos de posicionamento discursivo "linear" e "pictórico" Bakhtin (2009, p. 156). O estilo linear é característico de ideias de "senhores do pensamento" de uma época verbalmente expressa, algumas tarefas fundamentais, lemas etc (BAKHTIN, $2010 \mathrm{p}$. 294, grifos do autor). Levamos em conta aqui, a posição que um discurso ocupa na 


\section{SEMINÁRIO DE PESQUISA EM CIÊNCIAS HUMANAS - SEPECH \\ Humanidades, Estado e desafios didático-científicos \\ Londrina, 27 a 29 de julho de 2016}

hierarquia social. Neste aspecto, quanto mais saliente o sentimento de hierarquia nas situações de negociação, mais nítidas e definidas as fronteiras dos posicionamentos e, consequentemente, menor a abertura para réplicas que desestabilizam significados. Quanto mais impessoal a maneira de retomar o discurso do outro, quanto mais categórica e forte a palavra que retoma significados, menor a apreensão apreciativa e mudanças no modo de compreender o que está sendo discutido. A força do estilo discursivo linear se mantém pelos contornos exteriores nítidos do discurso citado, pela impessoalidade e enfraquecimento da voz que retoma e, consequentemente, fortalecimento do posicionamento do discurso citado, que adquire contornos de discurso de autoridade.

Ao contrário da enunciação discursiva revestida de autoridade, o estilo discursivo pictórico potencializa diferentes vozes nos processos argumentativos. Neste sentido, a língua, explica Bakhtin (2009, p. 156), "elabora meios mais sutis e mais versáteis para permitir ao autor infiltrar suas réplicas e seus comentários no discurso de outrem. O contexto narrativo esforça-se por desfazer a estrutura compacta do discurso fechado, por absorvê-lo e apagar suas fronteiras". Vale dizer que o estilo discursivo pictórico é desprovido de autoritarismo ideológico e desta maneira ele apaga contornos exteriores explícitos da palavra do outro pelo movimento discursivo fluído e mais individualizado que imprime "coloração lexical autêntica" por entoações, senso de humor, ironia, encantamento ou desprezo.

Neste movimento, crenças exercem forças que se inter-relacionam de maneira antagônicas criando zonas de conflito e dúvidas que desenvolvem situações questionadoras de práticas dadas como acabadas e prontas, estas forças são denominadas "centrífugas" Bakhtin (2009). Diferentemente delas, "forças centrípetas" criam zonas de conformidade pela simetria, afinidade e alinhamento discursivo que fazem com que as relações sociais se mantenham em harmonia, cristalizem saberes e práticas ideologicamente constituídas.

Estas distinções são relevantes e possibilitam análise da maneira que enunciados argumentativos figuram na negociação de significados e aprendizagem expansiva. A análise está orientada pela seguinte pergunta: Quais as implicações da recorrência de discurso de autoridade e internamente persuasivo para o desenvolvimento de aprendizagem expansiva?

A partir do objetivo e questionamento deste estudo, olhamos para o desenvolvimento de aprendizagem expansiva pelas lentes da análise de discurso crítica (ADC) cuja concepção de discurso presume o uso da linguagem como forma de prática social (FAIRCLOUGH, 2003) e o (s) processo (s) de aprendizagem estão interrelacionados à prática discursiva que, por sua vez, envolve processo (s) de sentido (s). Elegemos intertextualidade (RAMALHO; RESENDE, 2011; FAIRCLOUGH, 2003) como categoria analítica que possibilita investigar as implicações da ocorrência de discurso de autoridade e discurso internamente persuasivo no desenvolvimento de aprendizagem expansiva. Mecanismos linguísticos descritos em Liberali (2013) são igualmente relevantes para esta investigação, de modo especial, os mecanismos lexicais que dão sustentação à argumentação por experiências vividas, conhecimentos científicos, metáforas, expressões próprias; os mecanismos conversacionais, marcados por repetições, complementação, exclamações, pausas, questionamentos, permeabilidades; os mecanismos de coesão nominal que permitem investigar a conexão entre argumentos, compartilhamentos, retomadas, expansão de significados; os mecanismos de valoração em que as participantes marcam seus posicionamentos por 


\section{SEMINÁRIO DE PESQUISA EM CIÊNCIAS HUMANAS - SEPECH \\ Humanidades, Estado e desafios didático-científicos \\ Londrina, 27 a 29 de julho de 2016}

meio de adjetivação, de expressões apreciativas, depreciativas, identificatórias e descritivas; os mecanismos de modalização que indicam aspectos de obrigatoriedade, possibilidade, probabilidade, compreensão de ideias como única verdade, conformidade, julgamento; os mecanismos de distribuição de vozes que denotam inclusão ou apagamento de vozes, envolvimento do outro no discurso próprio; os mecanismos de proferição, marcados por silêncios, pausas, risos, ritmos de fala (simultaneidade); e os mecanismos de troca de turnos, observáveis nas interrupções, pausas, mudanças de tópicos nos conflitos, tomada de turnos, controle de turnos, ênfase, complementação.

Organizamos o texto de maneira a apresentar na primeira seção as linhas gerais sobre as quais apoiamos teórica e metodologicamente o estudo. Tratamos, em seguida, do contexto pesquisado, dos procedimentos de coleta e análise dos dados. As duas últimas seções do texto estão voltadas à análise e interpretação de trechos selecionados de encontros de formação continuada de professoras de inglês para crianças. Este estudo é um recorte de uma pesquisa realizada como parte do doutoramento, realizado pela primeira autora deste texto. Outros estudos decorrentes deste projeto podem ser lidos em Gimenez et al (2013), Coradim e Tanaca (2013), Tanaca e Mateus (2014).

\section{CONTEXTO E DADOS ANALISADOS}

Os dados analisados são parte da transcrição de gravações de três encontros de formação continuada de professoras de inglês do projeto Londrina Global (LG), desenvolvidos em escolas municipais de Londrina PR. As gravações foram feitas em 2013, ano em que o projeto de Desenvolvimento de Atividade de Ensino de Inglês para crianças (DAEIC/LEM/UEL), proposto e coordenado pela prof. ${ }^{a}$ Dr $^{\mathrm{a}}$ Denise Ortenzi, participou de cinco das dez reuniões de formação continuada, com objetivo de promover o desenvolvimento da atividade prática de ensino de inglês nos anos iniciais, bem como gerar conhecimento empírico sobre essa experiência. Organizamos as transcrições em dois conjuntos. O conjunto 1 é constituído de transcrições dos encontros de formação coordenados pelo projeto $L G$ e o conjunto 2 é formado pelas transcrições dos encontros pelo projeto DAEIC.

Os dois conjuntos de transcrição foram organizados em partes denominadas "sequências interacionais temáticas", a partir da duração dos temas discutidos. Analisamos neste trabalho a sequência interacional temática "partes da casa" com intervalo de duração entre 0:01:06 a 0:07:47 do dia 24/05/2013; e 1:48:33 a 2:11:00 do dia 8/11/2013, do conjunto de dados 1. Articulamos análises desta sequência à sequência interacional temática "rotina de sala de aula", com intervalo de duração 0:35:55 a 1:07:17 do dia 20/09/2013, do conjunto de dados 2. A sequência interacional temática "partes da casa" trata da negociação de uma atividade de ensino, denominada "partes da casa", constituinte do material didático "Host Family", coletivamente construído nos encontros de formação continuada.

Analisamos, a seguir, o modo como vozes são retomadas nas situações de negociação de significados da atividade "partes da casa" nestas datas, pela comunidade de prática Londrina Global constituída de 39 professoras com formação acadêmica em Letras ou formação em Pedagogia (com curso de Inglês em Instituto de Idiomas), experiência em alfabetização de língua materna e ensino de inglês para crianças. Com 


\section{SEMINÁRIO DE PESQUISA EM CIÊNCIAS HUMANAS - SEPECH \\ Humanidades, Estado e desafios didático-científicos \\ Londrina, 27 a 29 de julho de 2016}

exceção da primeira autora e das coordenadoras Rafaeli e Denise, todos os nomes são fictícios a fim de garantir anonimato aos pesquisados.

\section{ANÁLISE E INTERPRETAÇÃO DE DADOS}

A sequência interacional temática "partes da casa" apresenta uma atividade composta pela ilustração das partes de uma casa, com objetos numerados dentro de cada parte (lavanderia, garagem, quartos, banheiro, cozinha, sala de estar e jardim) e, abaixo desta ilustração, quatro colunas de vocabulário referentes aos objetos numerados nas partes da casa. $\mathrm{O}$ enunciado da atividade orienta alunos a colocarem números nas colunas de vocabulário, de acordo com números nas partes da casa. Dezenove professoras, Rafaeli e Jozélia iniciam a discussão em 24/05 a partir da maneira como a atividade "partes da casa" está configurada. A argumentação desenvolvida possui, epistemologicamente, traços da argumentação como diálogo (LIBERALI, 2013) que caracterizam o ambiente de formação e a aprendizagem como colaborativo-dialógico (MATEUS, 2005). O compartilhamento de experiências vividas e a articulação de vozes marca o processo de negociação de significados da atividade.

O diálogo é iniciado pelas professoras Miriam e Milena: 0:01:06-posso dar mais uma sugestão? Mas, talvez se antes tivesse um exercício de ligar o desenho à palavra; 0:01:41-Miriam- eu achei muita coisa nas partes da casa ali, naquela questão"; Miriam- 0:01:48- Pode ser assim, as partes da casa, quarto, sala e alguns objetos. Milena- 0:01:37- Eu achei, também.

A modalização discursiva destacada nas falas expressa convergência de pontos de vista, estabelece distância entre as professoras e o que elas dizem abrindo, consequentemente, espaço e poder para outras vozes decidirem, compartilhadamente, a criação ou não de uma atividade, anterior a "partes da casa. A abertura cria a possibilidade de constituir prática argumentativa "internamente persuasiva" caracterizada por réplicas no movimento de alternância de vozes na negociação de significados (BAKHTIN, 2010).

A predominância de turnos de fala modalizado continua com a professora Roberta que retoma e compartilha da opinião de Miriam de "muita coisa". Em seguida, Roberta descreve as experiências e adaptações que ela realiza com a atividade: 0:03:14Eu achei que foi muito vocabulário de uma vez, né? Porque eles estão vendo a casa, as partes da casa. "Eu introduzi no meio um exercício, eu nem estou com ele aqui, mas uma folhinha, pegava um ponto da casa..."; "eu peguei livro, né? Eu peguei de um livro". Então, na cozinha e na lavanderia, ai tinha fogão, essas coisinhas, né? Até um outro vocabulário de algumas palavras que são mais comuns como (NE), né? Essa coisa assim, né?"

Com o olhar voltado para local-contexto-objeto-conteúdo da prática argumentativa de Roberta, identificamos que a professora traz a voz dos alunos para respaldar a atitude de inserir outras atividades e recursos na ação de ensino. Os elementos de ligação de sua argumentação estão pautados pelo raciocínio de ações e adaptações de cunho prático (LIBERALI, 2013). Ainda que as escolhas lexicais referentes às adaptações da atividade, de senso comum e prático, constituam significado impreciso do que e como a professora adapta, assinalamos que ela exerce papel de agente no contexto de ensino e formação ao criar e compartilhar atividades compatíveis com nível de aprendizagem dos alunos. 


\section{SEMINÁRIO DE PESQUISA EM CIÊNCIAS HUMANAS - SEPECH \\ Humanidades, Estado e desafios didático-científicos \\ Londrina, 27 a 29 de julho de 2016}

As reflexões e ações explicitadas tanto por Roberta como por Talita, que passam a dominar e alternar turnos de fala no processo de negociação de significados da atividade "partes da casa", estão norteadas por pragmatismo e senso prático. A argumentação desenvolvida por elas, como ilustramos na transcrição seguinte, apresenta estilo característico de discurso internamente persuasivo, com questionamentos abertos ao final das falas indicando abertura, retomadas e alternâncias de falas com coloração lexical autêntica e individualizada marcada por entonação discursiva e, expressões de cunho avaliativo depreciativo da atividade, com forte carga emocional que denota adesão ao que é dito: Roberta-0:04:17- Só que aí, por exemplo, na primeira versão, a página está muito confusa. Isso aí que eu ia falar. Então, tem número que a criança não sabe, por exemplo, se é cama se é quarto/ Talita-0:04:30-: [fala simultânea] Ah! Sim... Nossa! Esse exercício ficou difícil, hein, gente! Judiou, hein?/ Roberta0:04:35- Lugar estranho para a criança. Então, a criança não sabe o que que é, e até a gente... eu fiz tudo primeiro/ Talita-0:04:36- [fala simultânea] Eu fiz primeiro, também./ Talita-0:04:49-[interrompe fala de Roberta] Eu errei um monte, por causa desses números.(setas representam entonação oral)

A argumentação é sustentada pela prática vivida. Ao relatarem ações de ensino, Roberta e Talita projetam a ethos discursivo, imagem de si Liberali (2013), como de professoras experientes porque colocam a atividade em prática e por este motivo expressam segurança no falar. Embora as avaliações da atividade ocorram com escolhas lexicais e repertório linguístico de senso comum, Roberta e Talita assumem no contexto de negociação de significados da atividade "partes da casa", o papel de "mestres de raciocínio" (LIBERALI, 2013) pelo modo como se posicionam e direcionam a (re) configuração da atividade em foco. Elas reagem, justificam e explicam os motivos da necessidade da adaptação, apontada por elas e também pela professora Miriam.

Embora Talita e Roberta busquem, frequentemente, a opinião do grupo sobre o que elas dizem, os mecanismos de proferição como entonação e timbre de voz, ritmo acelerado de fala com tomadas dos turnos de Roberta por Talita, envolvimento emocional, expresso pelo uso de adjetivos e expressões avaliativas de cunho descritivo, caracterizam o relato das experiências de sala de aula das professoras como discursos de autoridade. A prática de ensino vividas por elas constituem "pontes fortes de quadros de referência amplamente aceitos" (MATEUS, 2013, p. 14) e, assim, as duas dominam os turnos de fala e o silêncio das demais professoras se estabelece da negociação de significados da atividade "partes da casa".

Compreendemos o silêncio como aspecto discursivo que se funda e também fundamenta (ORLANDI, 1995) o sentido das palavras de Roberta e Talita; como lócus que atribui validade e veracidade à argumentação desenvolvida pelas professoras "mestres de raciocínio" que professam e expressam as práticas que vivenciam com a atividade em análise. Supomos que nenhuma resposta e participação nula significam e constituem respostas com múltiplos significado: medo de falar, insegurança pelas relações hierárquicas e de poder, distanciamento entre a experiência de algumas e a falta de experiência de outras, alienação do processo de aprendizagem (LEONTIEV, 1978), isto é, falta de investimento pessoal na atividade principal e envolvimento em atividades paralelas, desânimo, frustração e outros sentidos gerados nas condições subjetivas e concretas que contituem a prática docente. Esse posicionamento implica dizer também que o silêncio gera um apagamento de vozes e constitui o pressuposto de que existe um "contrato implícito de participação" (LIBERALI, 2013) em que discursos de autoridade, 


\section{SEMINÁRIO DE PESQUISA EM CIÊNCIAS HUMANAS - SEPECH \\ Humanidades, Estado e desafios didático-científicos \\ Londrina, 27 a 29 de julho de 2016}

constituídos por práticas vividas e compartilhadas, prevalecem na negociação de significados. Neste movimento, o discurso internamente persuasivo vai perdendo espaço para o discurso de autoridade e na condição de professoras experientes, Roberta e Talita passam a assumir o papel de porta voz das professoras que não expressam opiniões próprias e não reagem ao que é falado.

Com intenção de olharmos para aprendizagens em movimento longitudinal, direcionamos olhar para a prática argumentativa do encontro de formação de 8/11/2013, no período da sequência interacional de $1 \mathrm{~h} 48 \mathrm{~min}$ até $2 \mathrm{~h} 11 \mathrm{~min}$ de gravação em áudio. A retomada da negociação de significados desenvolvida em 24/05/2013 pela professora Roberta reitera sua discordância com a atividade: Roberta - 1:50:41 - Bom, o que eu percebi é que essa atividade é muito longa. É uma atividade muito longa para ser atividade inicial porque assim quando você insere uma informação nova e com muito vocabulário e já pede um exercício, é complicado.

A professora Roberta passa a conceituar a atividade "partes da casa" como "atividade inicial", defendendo a ideia de que a atividade "partes da casa" não pode ser considerada "atividade inicial" do material didático Host Family. Esta escolha lexical explicita que Roberta passa a olhar para tipos de atividade que compõem material de ensino em relação ao nível de aprendizagem dos alunos. Os conceitos "atividade inicial", "atividade principal" foram tratados na formação do projeto DAEIC de 20/09/2013, sequência interacional "análise, rotina de sala de aula", conduzida pela professora Denise Ortenzi, no recorte 0:35:55-1:07:17, com base no que dicute Cameron (2012). Vejamos um trecho onde destacamos a texturização da professora Denise, no conjunto de dados 2, retomadas pela professora Roberta, no encontro do Projeto Londrina Global: 0:39:17-0:40:41- Então essas dai já poderiam estar na parte mais ampliada da aula, né? Qual a atividade principal, a core activity, um jogo, por exemplo, ou ele é uma atividade mais rapidinha para introduzir a aula, ou ela é a core activity, né? Que atividades você precisa fazer para levar o seu aluno a fazer aquela atividade que você quer que ele faça, eu vou levar uma, duas ou talvez três até a atividade principal que eu quero que ele faça, né? E depois a conclusão, a despedida, né?

A argumentação desenvolvida pela professora Denise orienta para tipos de atividades de ensino relacionadas às fases de planejamento de uma aula de inglês para crianças, sendo elas, respectivamente: atividade (s) introdutória(s), atividade principal e conclusão. A professora associa a fase de introdução às atividades rápidas, considerando o objetivo de sinalizar início da aula de inglês. A atividade principal, pela argumentação desenvolvida por Denise, pode necessitar de várias atividades/aulas anteriores a ela, realizadas em uma sequência que desenvolvem conhecimentos suficientes para aluno realizar a atividade principal. O conteúdo desta fala também é recuperado por Jozélia na argumentação sobre a atividade "partes da casa", em 8/11/2013: 1:52:50 - Bom! o que a Roberta falou, eu fico aqui relembrando dos encontros da Denise e associando com o nosso. Então, como que vocês vêem a relação do que a gente está vendo nos encontros do projeto com o que a gente está fazendo, eu consegui fazer uma ponte agora, não sei. O que vocês conseguem relacionar? Silêncio...

A fala inicial de Jozélia retoma a voz da professora Roberta com intenção de trazer à tona conteúdo de formação do projeto DAEIC. Pela análise da relação entre conteúdo, contexto e papéis desempenhados na situação enunciativa, identificamos contornos do conteúdo de formação do projeto DAEIC nesta fala. Estes contornos estão reiterados no questionamento buscando identificar se as professoras têm a mesma 


\section{SEMINÁRIO DE PESQUISA EM CIÊNCIAS HUMANAS - SEPECH \\ Humanidades, Estado e desafios didático-científicos \\ Londrina, 27 a 29 de julho de 2016}

percepção da coordenadora, ou seja, se estabelecem relação entre conteúdos de formação do projeto DAEIC com o desenvolvimento de atividades para material didático do projeto Londrina Global. Enquanto forma peculiar de constituir significados, a construção metafórica "fazer ponte" explicita a necessidade da coordenadora estabelecer elos entre o conteúdo das formações para a negociação de significados de atividades desenvolvidas pelas professoras. Supomos que a ausência de falas como resposta durante $1 \mathrm{~min} 10 \mathrm{sec}$ pode representar falta de compreensão da pergunta e/ou, por outro lado, dificuldade e ausência de estabelecimento de relações entre os objetos questionados. A prática argumentativaa inquisitiva da coordenadora Jozélia cria espaço para participação e, ao mesmo tempo, estabiliza e fortalece o conteúdo e a formação desenvolvida pelo projeto DAEIC.

Supomos esta prática discursiva questionadora permeada por relações de poder marcadas, por sua vez, pelos papéis e lugares sociais ocupados por quem enuncia (coordenadora Jozélia) e pelo discurso enunciado (da coordenadora Denise) constituindo discurso de autoridade, com aparência de internamente persuasivo. $\mathrm{O}$ movimento discursivo que articula e retoma significados constituídos nos encontros de formação continuada do projeto DAEIC parece provocar tanto expansão da compreensão da atividade de ensino "partes da casa" por parte de Roberta e Jozélia, como resistência e tensão teórico-metodológica na maneira de conduzir esta atividade, uma vez que algumas professoras possuem e compartilham experiências e práticas, com teorias implícitas, que constituem quadros de forte e ampla referência profissional.

Entendemos que o movimento de expansão-resitência na negociação de significados da atividade de ensino em foco, decorre do confronto de discursos de autoridade de diferente natureza (constituídos pelas professoras "mestres de raciocínio" - experientes) e discursos de autoridade (constituídos pelo conhecimento permeado de hierarquias e relações de poder). Acreditamos que há espaço para posicionamentos e múltiplos acabamentos no processo de negociação de signficados e para o desenvolvimento da aprendizagem expansiva. O estilo discursivo linear que busca manter presente conteúdos de formação do projeto DAEIC entra em choque com o modo como as professoras vêm desenvolvendo atividades para material de ensino. A argumentação, contra-argumentação e discurso internamente persuasivo perdem espaço para o silêncio e para participação reiterada das mesmas professoras que possuem coloração discursiva autêntica na retomada de vozes de colegas, nos questionamentos, nos modos de significar e explicitar adapatações com atividades e, por outro lado, representam discurso de autoridade na definição dos contornos e configuração da atividade "partes da casa".

\section{CONSIDERAÇÕES FINAIS}

Acreditamos que a formação do projeto DAEIC percorre caminhos diferentes dos caminhos trilhados pela formação do projeto $L G$, cuja aprendizagem ocorre em estreita relação com práticas vividas e compartilhadas. Caracterizamos a aprendizagem desenvolvida pelo processo de negociação de significados da atividade "partes da casa" como movimento de criação, troca e hibridização entre diferentes contextos culturais e padrões de competência profissional, explicitados pela agência exercida pela professoras nos processos de adaptação de atividade que foram compartilhados. 


\section{SEMINÁRIO DE PESQUISA EM CIÊNCIAS HUMANAS - SEPECH \\ Humanidades, Estado e desafios didático-científicos \\ Londrina, 27 a 29 de julho de 2016}

Compreendemos que a constituição e predomoninância de discursos de autoridade ocorre em estreita relação com as práticas sociais que os constituem e que, por sua vez, imprimem contornos da maneira com as atividade em negociação se configura. Estes discusos derivam do local e dos papéis sociais desempenhados por quem enuncia, da experiência profissional compartilhada que constituem contornos de discusos de autoridade, advindos da prática atuando como forças centrípetas que nutrem, fortalecem as aprendizagens relatadas pelas professoras. Estas forças entram em choque, nos processos de negociação de significados, com forças centrífugas que inserem novas maneiras de (re)significar. Assim, a aprendizagem expansiva como processo que conduz para a formação de conhecimentos e conceitos teóricos ocorre permeada de choques teóricos e metodológicos explicitados ora pelo estilo discursivo pictórico, ora pelo estilo discursivo linear. Entendemos a aprendizagem expansiva, neste campo de forças, como processo que transforma e cria cultura marcada por conflitos que potencializam mudança na maneira de planejar, criar, conceituar e significar atividades de ensino. Os conteúdos e aprendizagens desenvolvidas pelo projeto DAEIC não garantem transformação de práticas e atividades de ensino da comunidade, mas representam forças centrífugas que provocarem desestabilização e questionamento do status quo de ações e práticas compartilhadas.

Os processos de negociação de significados e aprendizagens contam, por outro lado, com "forças centrípetas" (BAKHTIN, 1997) que por crenças e fazeres consensuais compartilhados, mantém e sedimentam zonas de conformidade que fazem com que as práticas, aprendizagens e conhecimentos existentes continuem. O silêncio que se funda e fundamenta significados nos processos de negociação da atividade em análise neste estudo pode estar situado entre as forças centrípetas, sua presença pode estar estreitamente relacionada à falta de estabelecimento de "pontes" entre conteúdo das formações desenvolvidas pelas formações LG e DAEIC.

\section{REFERENCIAS}

BAKHTIN. M. Estética da Criação Verbal. Introdução e tradução do russo Paulo Bezerra $-5^{\mathrm{a}}$ ed. São Paulo: Editora WMF Martins Fontes, 2010.

Marxismo e filosofia da linguagem: problemas fundamentais do método sociológico na ciência da linguagem. São Paulo: Hucitec, 1997.

CAMERON. L. Teaching Language to Young Learners. $17^{\mathrm{a}}$ edição. Cambridge University Press 2012.

EDWARDS, A. Being an expert Professional Practitioner: The relational turn in expertise. Springer. Vol.3, 2010.

ENGESTRÖM. Y. Learning by expanding: An activity-theoretical approach to developmental research. Helsinki: Orienta-Konsultit.1987.

ENGESTRÖM, Y.; SANNINO, A. Studies of expansive learning: foundations, findings and future challenges. Educational Research Review, v. 4, 2010, p.1-24. 


\section{SEMINÁRIO DE PESQUISA EM CIÊNCIAS HUMANAS - SEPECH \\ Humanidades, Estado e desafios didático-científicos \\ Londrina, 27 a 29 de julho de 2016}

FAIRCLOUGH. N. Discourse and social change. Cambridge: Polity Press, 1992. Discurso e mudança social. Tradução de Isabel Magalhães. - Brasília: Editora Universidade de Brasília, 2008.

2003

Analysing Discourse: textual analysis for social research. New York: Routledge,

GIMENEZ, T; TANACA, J.J.C; PERES, R.C.V; VIEIRA, A. The introduction of English Language Learning at Early Stages of Schooling: the experience of Londrina Global. Linguagem e Ensino. V. 16, 2013, p.343-362.

GIMENEZ, T. A ausência de políticas para o ensino da língua inglesa nos anos iniciais de escolarização no Brasil. In: NICOLAIDES, C.; SILVA, K.A.; TILIO, R.; ROCHA, C.H. Orgs. Política e políticas linguísticas. Campinas: Pontes e ALAB, 2013.

T.; TONELLI, J.R.A. Building a curriculum for young learners: a Brazilian experience. International Journal of English Language and Translation Studies. v.1, n.3, 2013, p. 92-101.

Guia Curricular para Língua Inglesa: Educação Infantil e Ensino Fundamental. Subsídios para professores e gestores. Londrina, 2013. Disponível em: http://www.uel.br/eventos/epic/pages/arquivos/Guia\%20Curricular\%20versao\%20final, acesso em 01/05/2016.

JOHNSON. K. Second Language Teacher Education. A Sociocultural Perspective. Routledge. 2009.

LAVE, J; WENGER, E. Situated learning: legitimated peripheral participation. Cambridge: Cambridge University Press, Cambridge, 1991.

LAKOFF, G; JOHNSON, M. Metáforas da Vida Cotidiana. Cidade: Editora, 2002

LEONTIEV, A. Activity, Consciousness, and Personality. Traduzido do russo para o inglês por Marie J. Hall. Progress Publishers, 1978. Disponível em http://lchc.ucsd.edu/MCA/Paper/leontev acessado em 11de julho de 2003.

LIBERALI, F. Argumentação em Contexto Escolar. Campinas: Pontes Editores, 2013.

LIBERALI, F.; MAGALHÃES, M.C.C. Formação de professores e pesquisadores: Argumentando e compartilhando significados. In: TELLES, J.A. Org. Formação inicial e continuada de professores de línguas: dimensões e ações na pesquisa e na prática. Campinas: Pontes, 2009, p. 43-66.

MATEUS, E. Atividade de aprendizagem colaborativa e inovadora de professores: ressignificando as fronteiras dos mundos universidade-escola. 2005. 327 p. Tese (Doutorado em Linguística Aplicada e Estudos da Linguagem) - Pontifícia Universidade Católica de São Paulo, São Paulo, 2005. 


\section{SEMINÁRIO DE PESQUISA EM CIÊNCIAS HUMANAS - SEPECH \\ Humanidades, Estado e desafios didático-científicos \\ Londrina, 27 a 29 de julho de 2016}

. Práxis colaborativa e as possibilidades de ser-com-o-outro. In: SCHETTINI, R. H. HAWI, M.M.; SZUNDY, P.T. Orgs. Vygotsky: uma (re)visita no início do século XXI. São Paulo: Andross, 2009. p. 17-52.

. Por uma abordagem sócio-cultural da aprendizagem do professor. In: MACHADO, L.T. [indicar autores]. Orgs. Aspectos da linguagem: considerações teórico-práticas. Londrina: EDUEL, 2006, p. 95-113.

Investigando Oportunidades de Aprendizagem em Práticas Situadas: Contribuições de Pesquisas Sociocríticas para Formação de Professores/as de Línguas. In: MATEUS E.; OLIVEIRA, N. Orgs. Estudos Críticos da Linguagem e Formação de Professores/as de Linguas: Contribuições Tórico-Metodológicas. Campinas: Pontes, 2014, p. 339-364.

ORLANDI, E.P. As formas do silêncio: no movimento dos sentidos. 3. Ed. Campinas: Ed. Unicamp, 1995.

Projeto de pesquisa e Extensão: Desenvolvimento de Atividades de Ensino de Inglês para Crianças através da produção coletiva de material didático (NAP/UEL), 2013. Disponível em: http://www.uel.br/cch/nap/pages/projetos/em-andamento.php, acesso em 1/05/2016.

RAMALHO V.; RESENDE V. M. Análise de discurso (para a) crítica. Campinas: Pontes, 2011.

ROCHA, C.H. Reflexões e propostas sobre língua estrangeira no Ensino Fundamental I. Plurilinguismo, Multiletramentos e Transculturalidade. Campinas: Pontes, 2012.

ROCHA, C.H.; TONELLI, J.R.; SILVA, K.A.S. Língua Estrangeira para Crianças: ensino-aprendizagem e formação docente. Campinas: Pontes, 2010.

STEINER, V.J. Creative Collaboration. New York: OUP, 2000, p. 123-150.

TONELli, J. R. A. Novas Propostas e Novos Desafios no Ensino de Línguas Estrangeiras para Crianças. In: CONGRESSO LATINO AMERICANO DE FORMAÇÃO DE PROFESSORES

DE LÍNGUAS - CLAFPL, II, 2008, Rio de Janeiro. Anais. Rio de Janeiro, 2008.

, J. R. A.; CRISTOVÃO V. L. C. O papel dos Cursos de Letras na Formação de Professores de Inglês para Crianças. Calidoscópio, v. 30, n. 01, 2010, p. 65-76.

WENGER, E. Communities of practice: learning, meaning and identity. Cambridge: Cambridge University Press, 1998. 